\title{
Are We What We Eat? Food Metaphors in the Conceptualization of Ethnic Groups
}

\author{
To Henry E. Darby, \\ The man who has always fought against racism
}

Irene López-Rodríguez (Calgary, Canada)

\begin{abstract}
Speakers of English often understand ethnic and racial differences in terms of food imagery. It is quite common in this language to encounter metaphors presenting different groups of people in terms of beans, rice, bread, cheese, apples or chocolate. Given the cognitive and social force of metaphor in our understanding of the world and of ourselves as well as the important role language plays as a channel through which ideas and beliefs are transmitted and perpetuated, such food images may offer a window on the (de)construction of ethnic identities and, ultimately, hide racist views against others who are different because of their skin color, physical features, languages and, obviously, diets.
\end{abstract}

\section{Foreign Children}

Little Indian, Sioux, or Crow Little frosty Eskimo,

Little Turk or Japanese, Oh! Don't you wish that you were me?

You have seen the scarlet trees And the lions over seas;

You have eaten ostrich eggs, And turned the turtle off their legs.

Such a life is very fine, But it's not so nice as mine: You must often as you trod, Have wearied not to be abroad.

You have curious things to eat, I am fed on proper meat;

You must dwell upon the foam, But I am safe and live at home.

Little Indian, Sioux or Crow,

Little frosty Eskimo,

Little Turk or Japanese,

Oh! Don't you wish that you were me?

(Robert Louis Stevenson 1913) 


\section{$1 \quad$ Introduction}

The attitudes of racial superiority conveyed in Stevenson's (1913) Foreign Children may, after all, not have changed so much since $19^{\text {th }}$-century imperial England - a time in which encounters with different peoples gave rise to a wide repertoire of metaphors whose main focus was on the dissimilarities between different cultural groups. So, just like the little child in the poem finds the dietary customs of others - be they Indians, Siouxes, Crows, Eskimos, Turks or Japanese "curious" for, unlike him, who is "fed on proper meat," those "have eaten ostrich eggs" and "turned the turtles off their legs," (ibd.) distinctive food continues to be a rich source of racist metaphors. In fact, there are examples galore reflecting the attitudes and beliefs held by a particular group towards others whose dietary customs seem alien to them. For example, the Germans refer to their Dutch neighbors as Käseköpfe (i. e. 'cheesehead'); whereas the British speak of the French as frogs, who, in turn see the latter as rosbif (i. e. 'roastbeef'). For Hebrews the Italians are loksh ('noodle') and both Japanese and Chinese are often seen as rice-eaters. The Mexicans resort to types of bread, bolillo ('bun') and cracker, when dealing with white people but the Portuguese prefer the chewing coca. Fruits such as apple and 香蕉('banana') appear to be the choices of US and Chinese when referring to Native Americans and Chinese people grown up in a Western country, respectively.

More explicit comparisons with food can be seen in fixed expressions that associate a particular nationality with an eating or drinking habit. So when English-speakers think of going boozing the nationalities that come up to their minds are the Irish (to drink like an Irishman), the Dutch (drunk as a Dutchman) and the Indians (drunk as an Indian) but the French associate drinking with the Polish (boire comme un Polonais) whereas the Spaniards with the Russians (beber como un cosaco) and the Danish with the Swedes (Full som Svensker).

Even in the field of humor food has become a fruitful domain to mark differences between human beings. Jokes often poke fun at other nationalities based on their eating habits, as seen in the so-called "What do you call" sequence in American English: What do you call a pool with a Mexican in it? Bean dip; What do you call a bunch of Indians in a Swimming Pool? Cocoa Pops or What do you call a bunch of White people in a Swimming Pool? Rice Bubbles, in which the punchline lies in the identification of the skin color or diet of people with different foodstuffs.

\section{$2 \quad$ Aim of the paper, approach \& methodology}

This paper attempts to offer a preliminary exploration of how racist views are often transmitted and perpetuated by means of food-based metaphors in English. Adopting a cognitive approach to figurative language metaphors are seen as cognitive mechanisms which enable the language user to make sense of complex, abstract, unfamiliar things - different people in the case of this article - in terms of more concrete, bodily experiences - food for the sake of this research.

Given the wide range of variation within the English-speaking world, the corpus gathered for this article attempts to be representative of the different varieties of this language. In this sense, not only are different language varieties of the language under study being considered (i. e. British, Irish, American, South African, Australian English, among others) but also diachronic and synchronic variation will be often brought to the fore in order to understand the coinage of 
some metaphors. As a matter of fact, because encounters with different peoples intensified during the colonial periods and because globalization is bringing more and more people together with their respective cuisines, databases and on-line sources together with dictionary and slang corpora will be consulted in order to provide a better insight into food-based metaphors applied to ethnic groups. ${ }^{1}$

At the outset, then, one must admit that there are shortcomings in the present article as regards the use of this methodology in the study of racist ideology. As a matter of fact, although the corpus gathered consists of 300 tokens and is fairly representative of different varieties within the English-speaking world, the metaphors analyzed are decontextualized; in other words, the focus is on isolated words as opposed to discourse units. Therefore, because the study is fundamentally theoretical in nature, how speakers feel or think when they are either the agent or the target of such racist metaphors is not considered here, but it could be a powerful area for future empirical research. Nonetheless, despite these obvious flaws, the article does hope to bring to the surface how racist ideologies about different ethnic groups are very often channeled and perpetuated by means of metaphors based on foods.

First, the paper will offer a brief introduction to Conceptual Metaphor Theory (3) since it will provide the analytical tools to unravel the motivations that have given way to the metaphors under study. The next section will focus on the folk cognitive model known as The Great Chain of Being metaphor (4), which will serve as a framework to understand how the use of food metaphors dehumanize people from different ethnic backgrounds and, therefore, are suitable to convey racist views. This will be followed by an overview of common food-based metaphors that pervade everyday speech in English (5). The pervasiveness of such figurative usages will be explored from the twofold dimension food has in people's lives, that is to say, from a biological and social perspective.

After that, the focus will shift to the study of ethnic metaphors based on foodstuffs in English (6). Some preliminary references will be made to common linguistic mechanisms which, having metaphor as their basis, target ethnic groups by enhancing differences among people. Then there is a classification with an analysis of the corpus gathered for this research. The following part will provide a discussion of how racist ideology is conveyed by means of these metaphors (7). Special attention will be paid to the construction of identity via metaphor, that is, to the power of metaphor in creating clear-cut boundaries between in-groups and out-groups; in other

\footnotetext{
1 The metaphors analyzed in this paper have been taken from different sources which include dictionaries such as the Oxford English Dictionary, Merriam-Webster Dictionary, Collins COBUILD Dictionary of Idioms, A Dictionary of Contemporary American Usage, Historical Dictionary of American Slang, A Dictionary of the Underworld, A Dictionary of Slang and Unconventional English, Roget's Thesaurus of English Words and Phrases, Thesaurus of Traditional English Metaphors, A Dictionary of Slang and Unconventional English. Along with these, the British National Corpus, Corpus of Contemporary American English and Corpus Concordance English have also been consulted. Finally, because internet provides a wealth of information, particularly when it comes to slang and racist slurs, the following sources have been included in the present study: A Dictionary of English Slang (www.peevish.co.uk/slang/), Dictionary of Races or Peoples (https://archive.org/details/dictionaryraces00folkgoog), Internet Racial Slang Database (www.pdftop.com/ebook/internet+racial+slur+database/), Online Etymology Dictionary (http://www.etymonline.com/), Racism in Advertising (http://owni.eu/2011/03/12/racism-in-advertising-50shocking-examples/), Racist Food Advertisements (www.complex.com/city-guide/2013/10/racist-food-advertisements/), The Free Dictionary (www.thefreedictionary.com/ethnic+slur), The Online Slang Dictionary (http://onlineslangdictionary.com/), The Racial Slur Database (www.rsdb.org/), Urban Dictionary (www.urbandictionary.com/define.php?term=slang), Wikipedia (http://en.wikipedia.org/wiki/List_of_ethnic_slurs).
} 
words, the gap between "the us" versus "the other." Finally, some conclusions will be drawn regarding the connection between food-based metaphors and racism (8).

\section{Conceptual metaphor theory}

Using metaphor is not like adding "spice" to speech. In other words, the non-literal use of "spice" in the previous sentence is not a mere rhetorical artifact that functions here as a playon-words for the sake of the topic of this paper but, as cognitive linguists argue, a reflection of the more general human tendency to categorize the abstract concept ideas in terms of the more concrete bodily experience of food.

In fact, as opposed to the traditional view, which regards metaphor as a special turn of language, that is, as a deviance from what is literal, usually with the purpose of adding more "flavor" to a text, that is, in the pursuit of an aesthetic purpose, examples like the above "spice" and "flavor", far from being isolated, form part of a systematic set of correspondences whereby ideas are understood in terms of food (e. g: food for thought, read voraciously, swallow one's words). In addition to this metaphorical substrate underlying everyday speech, the existence of similar metaphors in very different languages like Vietnamese ${ }^{2}$ (Anne vẫn luôn đọc ngấu đọc nghiến, Tôi thật không thể nuốt nổi câu nói đó, (Tôi) phải mất một lúc mới tiêu hóa được lý thuyết ấy), Spanish (lector voraz, sed de conocimiento, ideas frescas, tragarse las palabras, digerir la información, alimentar rumores) or Arabic ${ }^{3}$ (makajšbašs mon lqraja, had lfikra ma fiha tiba, šrmaltiha, ma tsartatliš), among many others, has given linguists food for thought, leading to the search for the roots of metaphor not in language but in thought and action (see Lakoff/Johnson 1980; Gibbs 1994, inter alia). So the advocates of Conceptual Metaphor Theory (henceforth CMT) locate metaphor in an interstitial position between language and thought.

What such a claim boils down to, resorting again to a food metaphor, is to the notion that such figurative culinary uses are not isolated but rather they belong to a system of metaphors which bring to the surface a mental mechanism that allows people to understand mental processes in terms of foodstuffs. Therefore, CMT regards metaphor as an essential mental phenomenon inherent to human beings which functions by establishing correspondences or mappings between two conceptual domains of experience. In this case, the source domain FOOD enables us to make sense of another experiential target domain IDEAS. Features are then projected from the source domain onto the target domain so that the second domain of IDEAS is partially understood in terms of the first one of FOOD (Barcelona 2003), as shown in table $1 .^{4}$

\footnotetext{
2 Examples taken from Phuong Tam (2009). They translate as 'Anne has always read voraciously', 'I just can't swallow that claim' and 'It took a while to digest the theory'.

${ }^{3}$ Examples taken from Berrada/M'sik (2007). This is the translation into English: 'He is never satiated from learning', 'This idea is tasteless', 'He digested the idea'.

4 The metaphor "ideas are food" has been widely studied across-languages. See: Newman 1997; Goschler 2005; Berrada/M'sik 2007; Maalej 2007; Jaggar/Buba 2009; Phuong Tam 2009; Khudhair 2011; Chiarung 2012; Faycel 2012.
} 


\begin{tabular}{|c|c|c|c|}
\hline $\begin{array}{l}\text { SOURCE DO- } \\
\text { MAIN (FOOD) }\end{array}$ & $\begin{array}{l}\text { MAPPING FEA- } \\
\text { TURES }\end{array}$ & $\begin{array}{l}\text { TARGET DO- } \\
\text { MAIN } \\
\text { (THOUGHT) }\end{array}$ & Linguistic metaphors \\
\hline Ingredients & Material & $\begin{array}{l}\text { Content or in- } \\
\text { formation }\end{array}$ & food for thought \\
\hline $\begin{array}{l}\text { Flavor \& proper- } \\
\text { ties of ingredients } \\
\text { (quality) }\end{array}$ & Taste/properties & Quality & sweet comments \\
\hline A recipe & $\begin{array}{l}\text { Steps to be followed to } \\
\text { achieve a goal }\end{array}$ & Instructions & a recipe for success \\
\hline $\begin{array}{l}\text { Preparation of } \\
\text { food/cooking }\end{array}$ & Creation & $\begin{array}{l}\text { Planning Pro- } \\
\text { duction }\end{array}$ & half-baked ideas \\
\hline Serving food & Giving & $\begin{array}{l}\text { Providing in- } \\
\text { formation }\end{array}$ & $\begin{array}{l}\text { serve up a number of } \\
\text { suggestions }\end{array}$ \\
\hline Feeding & Giving & $\begin{array}{l}\text { Providing in- } \\
\text { formation }\end{array}$ & $\begin{array}{l}\text { feed the media with sto- } \\
\text { ries }\end{array}$ \\
\hline Hunger/Thirst & Need & $\begin{array}{l}\text { Need for infor- } \\
\text { mation }\end{array}$ & $\begin{array}{l}\text { hunger/thirst/appetite } \\
\text { for knowledge }\end{array}$ \\
\hline Eating/Drinking & Absorption/Intake & $\begin{array}{l}\text { Taking infor- } \\
\text { mation }\end{array}$ & eat one's words \\
\hline Chewing & $\begin{array}{l}\text { To make something } \\
\text { smaller/easier }\end{array}$ & Considering & to chew over \\
\hline Swallowing & To process & Accepting & to swallow a claim \\
\hline Digesting & $\begin{array}{l}\text { To process } \\
\text { To accept }\end{array}$ & Understanding & to digest the news \\
\hline Regurgitating & To repeat & Remembering & $\begin{array}{l}\text { we have to regurgitate } \\
\text { everything we learned } \\
\text { on the final }\end{array}$ \\
\hline
\end{tabular}

Table 1: Graphic representation of IDEAS ARE FOOD in English. 5

Such mappings, according to CMT, appear to be grounded in embodied experience, that is, in the relationship that people establish with the world through their bodies. This notion of embodiment is definitely the basic ingredient within CMT to support the mental nature as well as the universality of conceptual metaphor. ${ }^{6}$

\footnotetext{
${ }^{5}$ For a detailed graphic representation of the metaphor IDEAS ARE FOOD see Khudhair 2011.

${ }^{6}$ For a detailed study of the concept of embodiment and its role in the creation of meaning, see Goschler 2005; Heine/Nguyen 2009 and Gibbs 2006.
} 
At first sight ideas and food have nothing to do with each other. Ideas are complex, abstract entities that cannot be physically grasped - though notice that grasp ideas is a common collocation in English meaning 'understanding' - unlike food, which is tangible, concrete, in other words, physical (see Johnson 1987). The way food enters the body is then projected onto the way ideas enter the mind and, by the same token, the quality and state of food together with the processes involved in food preparation and consumption are projected onto the different stages of the thinking process, as seen in the graph above.

Yet, although embodiment may certainly account for the existence of conceptual metaphors such as IDEAS ARE FOOD, it does neither explain the blockings of certain mappings from a source to a target domain (see Grady 1997) nor language variation (see Deignan 2005; Kövecses 2005, 2006). ${ }^{7}$ As regards the former, it seems clear that a conceptual metaphor like IDEAS ARE FOOD motivates linguistic expressions such as read voraciously or digest information but other activities that involve food are not mapped (e. g. people do not say *munch your words or *grind your ideas). In terms of the latter, even though speakers of English, German, Arabic or Japanese seem to share the conceptual metaphor IDEAS ARE FOOD, the linguistic rendering of such a metaphor differs among those languages. So whereas English something is hard to swallow finds the exact equivalent in German etwas ist schwer zu verdauen, Arabs and Japanese resort to another lexical item, it does not flow on my larynx and something is hard to chew, respectively (see Callies/Zimmermann 2002).

Metaphors, then, cannot be considered as an exclusive mental phenomenon stemming from first-hand experience since context, understood in its broadest sense (individual, social, regional, ethnic, cultural, social, diachronic or synchronic), also shapes metaphorical conceptualization. ${ }^{8}$ Hence, even though embodiment provides the basis for conceptual metaphors, all the elements that physical experiences entail will not be used in the creation of linguistic metaphors, but, on the contrary, only a few will be singled out by each group of people depending on the context or on what Kövecses (2005) terms "differential experiential focus". Metaphors, then, are partly universal, partly context-specific, and, as will be seen later on, this is glaringly obvious in the field of food metaphors given that because of geographic, religious, social or cultural reasons some foods will be preferred over others in the conceptualization of different ethnic groups. To whet your appetite, for instance, consider how the notion of success is understood as the quick sale of food in English, French and Spanish. Yet, the choice of food in these three

\footnotetext{
7 Grady (1997) offers a plausible solution to these problems by suggesting that conceptual metaphors do not provide the foundations for straightforward metaphorical mapping between body experience and thought. Rather, he argues, the relationship established between our body and our mind generates "primary" or "primitive" metaphors which serve as the skeleton on which metaphorical thinking will be built. These "primitive" metaphors show a direct correlation between our perceptions and our thoughts, that is to say, the metaphor is grounded on the basis of direct experience, not on linguistic evidence. On the other hand, the combination of primitive metaphors results in complex metaphors which do not necessarily map all the possible elements from the source to the target.

${ }^{8}$ In this sense Gibbs/Steen (1999) state that experience does not necessarily explain many of the metaphors outlined by cognitive linguists and people's experiences may not be a reflection of them. In a similar line MacArthur (2005) states that embodiment cannot always explain the spread and acceptance of many metaphoric themes for sometimes the experiential perspective of a speech community changes as time goes by. Hence, when a particular domain becomes obsolete and, therefore, people cannot perceive it physically, the most plausible mechanism enabling a figurative transfer to take place is found not in people's first-hand experiences but in cultural mediation.
} 
languages is completely different (hot cakes, bread and fritters, respectively) and certainly reflects those cultures. ${ }^{9}$

As opposed to the traditional or classical view of metaphor as a rhetorical artefact, this paper adopts the aforementioned cognitive approach in the analysis of food metaphors applied to people. However, given that terminology may be confusing at times, in the present study the term metaphor will be used as an umbrella term, that is, as a general term referring to cognitive mechanisms which imply a transfer of meaning and, therefore, it also comprises metonymy. ${ }^{10}$

\section{THE GREAT CHAIN OF BEING METAPHOR}

Before turning to some of the most common identifications of food-based metaphors used in the conceptualization of ethnic groups in English, it seems necessary to discuss a folk cognitive model known as THE GREAT CHAIN OF BEING (see Lovejoy 1936; Tilyard 1959; Lakoff/Turner 1989) because of its influence and repercussion in our understanding of the universe and of human beings. Briefly put, the major premise of The Great Chain of Being is that every existing thing in the universe has its place in a divinely planned hierarchical order which is pictured as a vertical chain where different entities occupy their corresponding position on the basis of their properties and behavior, that is to say, the more complex the being, the higher it stands. ${ }^{11}$

So at the bottom stand natural physical things such as the four elements defined by their structural and functional properties and behavior. Higher up are complex objects characterized by their structural and functional properties and behavior. After that come plants, with their biological functions and attributes. Then, animals, which are defined by their instinctual characteristics and behavior. Afterwards, human beings, who possess higher order attributes and behavior and, finally, celestial creatures, with their supernatural traits and behavior. Within each level there are sub-levels defined by different degrees of complexity and power in relation to each other (i. e. within the animal realm the lion is above the rabbit, which, in turn, is above the worm). This hierarchical organization, then, presupposes that the natural order of the cosmos is that higher forms of existence dominate lower forms of existence.

THE GREAT CHAIN OF BEING metaphor accommodates two types of conceptual mappings which enable us to see the chain as a top-down hierarchy in which higher level attributes and behavior are conceptualized in terms of lower-level attributes and behavior as well as a bottomup hierarchy in which lower-level attributes and behavior are understood in terms of higherlevel attributes and behavior. Hence, adopting a top-down approach, human beings can be understood via the instinctual and functional attributes and behavior of animals, plants and lower

\footnotetext{
9 The expressions in the target languages are as follows: to sell like hot cakes in English, venderse como churros in Spanish and vendre comme des petits pains in French.

${ }^{10}$ For a discussion about the differences between metaphor and metonymy, see Barcelona's (2003) Metaphor and Metonymy at the Crossroads, Dirven's/Pörings' (2002) Metaphor and Metonymy in Comparison and Contrast. Terminology is likewise problematic when it comes to terms such as racist slurs, derogatory nicknames, racist terms and ethnophaulisms. For the sake of this paper, all these terms will be used as practically synonymous.

11 The theory set forth here blends the so-called basic and extended versions distinguished by Lakoff/Turner (1989), according to whom the basic Great Chain of Being is concerned with the relation of human beings to lower forms of existence whereas the extended version focuses on the relationship between human beings, God, society and the universe.
} 
substances (e. g. he is a pig, she is a rose, he is a beefcake, she is a jewel) or, on the contrary, from a bottom-up perspective, people can be conceptualized through the divine qualities of supernatural creatures (e. g. he is an angel, she is a goddess, he is a demon).

The cultural framework provided by THE GREAT CHAIN OF BEING should be born in mind in the present analysis for, in general terms, when people are equated with foods, the identification is likely to convey a negative evaluation since people are being reduced to edible substances (see Lakoff/Turner 1989:170-180). In other words, dehumanization ${ }^{12}$ usually takes place when comparing people with lower substances in the Chain and, obviously, such linguistic and cognitive mechanisms are extremely useful to degrade groups that are not considered as the normative, which within society practically translates into the white male heterosexual. In fact, as will be seen in the case of ethnic groups, food-related metaphors are always at hand to disparage marginal groups such as homosexuals, women and people from different ethnic backgrounds. Interestingly, there seems to exist an overlap in food metaphors applied to females and homosexuals. By means of illustration, consider the figurative usages of cake, cream puff, fruit or sugar, which denote an effeminate or gay man and a woman indistinctly. ${ }^{13}$

What such an overlap reveals is that, within the cultural framework of THE GREAT CHAIN OF BEING, it seems logical that in order to degrade a man he should be compared with lower forms of existence, and these include women, who, in turn, can be belittled by comparing them to some foodstuffs. Therefore, because gay men are placed on the same sub-level of women, common metaphors will be used to refer to both groups (see Schulz 1975; Hughes 1991; Halupka-Rešetar 2003; Coviello/Borgerson 2004).

\section{$5 \quad$ Food as a source domain}

\subsection{Food \& the body: the biological dimension of food}

Food is of vital importance for the survival and well-being of people. Small wonder, then, that food - its shape, color, texture, smell, state and taste - is prone to be pervasively used as a source domain mapping. Parallels are often drawn between the shape of parts of the body with certain foodstuffs. Heads are seen as melons, breasts as pears and male genitalia as sausage. Along with appearance the spongy texture of cottage cheese resembles, to some extent, the puckered and dimpled skin surface caused by celullite and hence the metaphoric use of such products for this skin-related issue in English. Similarly, the symbolism of colors certainly translates into the preference for orangish and reddish fruits, with the connotations of passion attached to them, to identify attractive young women, as inferred from peach (see Calvo 1998; Václavíková 2010: 19-23). In the case of meat products it is their heavier consistency, when

\footnotetext{
${ }^{12}$ In this regard Mussolf (2012: 307) studies how the framework of THE GREAT CHAIN OF BEING is useful to understand racist metaphors because human beings are being reduced to foodstuffs: "The propensity of racists to dehumanize their victims both verbally and practically has in fact generated a whole research tradition in its own right, which has highlighted a systematic conceptual framework of the 'Great Chain of Being' (Lovejoy, 1936) that allows racists to denigrate their respective targets by 'demoting' them from humankind's central position in the Chain down to the 'lower' ranks of animals, plants, disease-engendering organisms or inorganic material."

13 According to the Historical Dictionary of American Slang cake refers to 'a gay man' and 'a woman'; cream puff denotes 'an effeminate man' and 'an attractive young woman'; fruit means 'an effeminate male or a male homosexual' and 'an easily seduced woman' whereas 'sugar' equally alludes to 'a gay man' and 'an attractive woman'.
} 
compared to fish, fruits and vegetables, that seems to explain its application to actions which require effort and skills (an argument with a lot of meat) as opposed to veg, which conveys the idea of laziness and illness (see Adams 1990). ${ }^{14}$ When it comes to taste, the general aversion from bitterness and attraction to sweetness may account for the conceptualization of (dis)agreeable experiences and temperament in terms of bitter and sweet tastes respectively (see Berrada/M'sik 2007). Hence, people speak synaesthetically of bitter comments and people and sweet words and people.

In like manner, the state of food finds its counterpart into the state of events, ideas, time or moral attitudes, among others. Ripe can be applied to ideas, time and situations if they are suitable and ready for action whereas moral corruption is condensed in the expression rotten apple. Even the smell of particular foods such as English fish (fishy) can be used when dealing with doubtful or suspicious situations given that the odor of such foods is off-putting. As a matter of fact, people, ideas, emotions, physical as well as mental states, sexual desire, knowledge, business and even life itself, are, commonly, understood in terms of edible substances.

People's experiences with food are fundamentally basic given that food is the main source of sustenance for the body. From a biological viewpoint, the body needs nourishment and the effects of food - whether in excess, moderation or deprivation - are certainly reflected in an individual's health state (both mental and physical). Such a strong correlation between body and food makes the latter an ideal source domain for metaphorical thought within CMT. In fact, as said before, the understanding of the world is largely mediated by our bodily experiences and it is, then, difficult to understand language in isolation from human embodiment. In this sense, not only are body parts a natural source domain for a wide repertoire of metaphors considerable attention has been paid to the semantic extension of body parts based on metaphor and metonymy, (see Heine et al. 1991a:124-131; Heine et al. 1991b:151-153; Rubba 1994; inter alia) - but also the processes the body is involved in (see Newman 1997: 225). Needless to say, the food domain certainly involves a series of embodied experiences which include hunger, thirst, tasting, chewing, swallowing, choking, digesting, vomiting, spitting, being satiated and excreting. Not surprisingly, such physiological activities are, in turn, used metaphorically in the conceptualization of reality. By way of illustration, consider how speakers of English conceptualize natural phenomena in terms of bodily processes: the eruption of a volcano is seen as vomitting lava; the absoption of water by soil is soaking; natural disasters like tsunamis and earthquakes swallow, eat and devour people; the upper part of the Earth is the crust and in slang rain is even pee.

Food and its concomitant practices play a vital role in our everyday lives. Food production, preparation and consumption have given way to a whole repertoire of culinary metaphors. Life itself is understood in terms of food (the spice of life, a recipe for success) and so is making a living (bring home the bacon or to be the breadwinner). Similarly, people themselves can be identified with different sorts of foodstuffs depending on their social status (a big cheese), physical activity (couch potato), gender (beefcake), sexual orientation (canned fruit), occupation (berry-pickers), personality (sweet), national or ethnic identity (rice-eaters) or through their

\footnotetext{
${ }^{14}$ In Where's the Beef? Adams (1990) analyses the language of meat eating cultures and shows how meat metaphors represent the essence of something while vegetable metaphors are usually associated with less desirable characteristics.
} 
body parts (apples, cucumber). Physical and mental states are likewise compared with food (to have a bun in the oven, to go nuts); just like more general situations (the icing on the cake). By means of food metaphors humans indeed think (food for thought), love (to be sustained by love), have sex (sexual appetite), compete both in professional and sports fields (eat one's business, to make hamburger out of someone) and even pray (get spiritual nourishment).

\subsection{Food \& society: the social dimension of food}

But regardless of the common need for nutrition, the significance of food for human beings transcends the biological and becomes a social phenomenon. Indeed, although biological need urges people to look for sustenance, it does not dictate them what to eat (see Hinnerová 2007: 26). Food choices are key to understanding not only cultures but also social relations (see Harris 1985; Gerhardt 2013). ${ }^{15}$ Aside from customs ranging from burping to showing politeness and appreciation, eating with the hands, chopsticks or silverware, sitting on the floor or at the table, food becomes an indicator or, using again a food metaphor, an ingredient in the construction of identity. ${ }^{16}$

As a matter of fact, food as a metaphor for the eater's identity is soon revealed in popular parlance because as the proverb says: "You are what you eat." One's existence is compared to one's eating habits and, therefore, how people perceive others heavily depends upon the foods they eat. Food choices may become tokens of identity on different levels, namely, individual, social, regional, racial, ethnic, national, etc. Some may choose to be a vegetarian or a vegan because of healthy or ethic reasons whereas others would consume certain types of food to reflect their social status since they can afford particular products. Religious practices will determine the consumption of or abstinence from certain foodstuffs, like the forbidden pork for Muslims and Jews or beef for Hindus, and specific foods will be associated with the typical gastronomy of a country, like potatoes in Ireland and rice in the case of China and Japan. So appear alimentary identities (see Bruegel/Laurioux 2002), in other words, a sense of belonging to a group determined by food choices.

Seen in this light, food becomes a social code (see Leeds-Hurwitz 1993), ${ }^{17}$ that is, a way of communication, for it conveys messages about social relations as well as social identities. In this sense, particular foodstuffs may encode messages of inclusion and exclusion, serving to draw boundaries between in-groups and out-groups. This value of food in the construction of identity makes its way into language by means of metaphor. Nowhere is this connection between food metaphor and identity made more obvious than in the field of taboo. The prohibition of certain substances which are regarded as inedible due to religious or cultural reasons frequently accounts for their figurative use as terms of opprobium and abuse (see Leach 1964: 23-

\footnotetext{
15 In this regard Mintz (1985: 4)points out that "What we like, what we eat, how we eat it, and how we feel about it are phenomenologically interrelated matters; together, they speak eloquently to the question of how we perceive ourselves in relation to others".

16 The concept of identity is problematic and there are countless definitions. Some scholars may even prefer to talk about identification. This paper adopts Scholliers' (2001: 9) definition of identity as "a person's own definition in terms of group membership, which entails intergroup behavior, or the identification of a person with the norms, ideals and manners of a group".

${ }^{17}$ For an overview of the semiotics of food, see Leeds-Hurwitz's chapter (1993) "Food as Sign and Code," which provides a good summary of the main theories put forward by Levi Strauss, Barthes or Mary Douglas, among others.
} 
63). For example, during the Middle Ages three cultures co-existed in the Iberian Peninsula, namely, the Muslims, the Jewish and the Christians. In 1492 the Catholic Monarchs achieved the religious and territorial unification of the Peninsula and although Catholicism was the official religion of the state, there was freedom of creed. However, because of reasons of power and prestige, many Muslims and Jewish decided to convert into Catholicism. These were seen with suspicion and were soon labelled as marranos (i. e. 'pigs') because eating of pork is forbidden by Muslim and Jewish religious law. Similarly, frogs are seen as non-edible for the British but not for the French, who regard this dish as a delicacy. Aversion towards such food by the British has materialized in language in the metaphorical use of frogs to refer to the French.

Apart from organizing people into different groups, food metaphors also serve to "distribute in an unequal way status to these groups by incorporating different appeals to the body and senses." (Korthals 2008: 79). Food metaphors then are commonly used to mark differences between ethnic groups and this holds true not only in the case of taboo but in the more general field of nutrients. Consider, for instance, the vegetable potato, which is part and parcel of the diet of most European countries. Yet since the $19^{\text {th }}$ century the Irish were called potato people by the English and the French called the Belgians fries eaters since such a tuber was a staple in the diets of these nations, becoming an essential product in their national cuisine (Scholliers 2001).

Food is certainly appropriate to delineate the "us" versus "the others" because the very process of food consumption represents a boundary between the outside and the inside of a person's body. ${ }^{18}$ It is precisely this "principle of incorporation," as Fischler (1988: 275) calls it, which makes food such a powerful material to separate the in-group from the out-group. ${ }^{19}$ As a matter of fact, food appears to be more powerful than language itself as a bearer of national identity. Research within groups of migrants has shown that even when language or other cultural forms of expression tend to be forgotten or lost by the following generations, food practices are in all likelihood retained (see Scholliers 2001: 8; Bell/Gill 1997).

Food is such an important badge of national identity that governments, regardless of their ideology, employ food imagery in the construction of nationhood. There are countless examples of political parties that resort to foodstuffs with the antithetical intention of either to exclude or include different groups. Pictorial and linguistic representations of groups in the guise of edible substances are part and parcel of nationalist discourse. In fact, as Smith (1994: 3-23) has affirmed, there seems to exist a gastronomy theory in the (re)construction of nations.

Food imagery is an essential component of nationalist propaganda. Pictorial representations of black people eating watermelon were commonplace in prints in ante-bellum America, since stereotypically black people were fond of this fruit.

\footnotetext{
18 Interestingly, this notion of boundary drawing condensed in food-related metaphors pervades immigration discourse. There is a wealth of metaphors conceptualizing a nation in the guise of a container whose boundaries are crossed by aliens, who, in turn, are represented as natural disasters, liquids and pressure built up (see CharterisBlack 2006), animals (see Santa Ana 1999) and diseases (see O'Brien 2003).

${ }^{19}$ In this regards, it is interesting to mention Leizaloa's (2006) work on food metaphors in the Basque borderland. This scholar reveals how territories located in the frontier resort to foods to mark identity.
} 
From a strictly linguistic point of view, food metaphors are part and parcel of nationalist discourse. Spiering's (2006) article "Food, Phagophobia and English National Identity" provides a good insight into the nationalist connotations attached to the image of the English beef-eater throughout history. Spiering states that although the connection between beef and nationalist sentiments in England can be traced back already to Shakespeare's time, it is in the $18^{\text {th }}$ century when this link is made stronger, precisely at a time of intense Anglo-French rivalry. Beef became a national symbol representing the opposing values of the French people. Hence in contrast to the Catholic French with their highly ornamented and sophisticated cuisine, beef embodied the virtues of Protestant simplicity that supposedly characterized the English people.

It goes without saying that dictatorial regimes also exploit images of food as markers of national identity. Rash's (2005) database of metaphors in Adolf Hitler's Mein Kampf is rife with references to foodstuffs and the same applies to communist discourses in China and the Soviet Union, as studied by Farquhar (2002) and Counihan/van Esterik (1997), inter alia. But even today's democracies resort to food imagery as a badge of national identity in their political discourses (see Bloemraad 2011). In "National Identity on a Plate" Raviv (2001) analyzes the role of food in the articulation of national identity within the Palestine-Israeli conflict and so does Hiroko (2008) in "Delicious Food in a Beautiful Country: Nationhood and Nationalism in Discourses on Food in Contemporary Japan," whereas in "Law, Food, and Culture. Mexican Corn's National Identity Cooked in "Tortilla Discourses" Hernández López (2008) shows how Mexico's discourse of national identity is heavily influenced by Mexican cuisine in general and by corn in particular.

Food metaphors are also an integral component of immigration discourse. A nation has traditionally been likened to a human body whose well-being largely depends on the foods consumed. ${ }^{20}$ Because immigrants are often perceived as a threat to a country, they tend to be presented as indigestible or poisonous food. When a government thinks that too many aliens are trying to enter the country, a digestive metaphor is used to convey the idea that assimilation cannot take place. In this way foreigners are conceptualized as an edible substance which is difficult to digest, as shown in the corpus of political metaphors culled by O'Brien (2003) in "Indigestible Food, Conquering Hordes, and Waste Materials: Metaphors of Immigrants and the Early Immigration Restriction Debate in the United States." A more damaging effect on the body pertains to poisonous food. In this case, it is not the quantity of immigrants but their quality in terms of culture that is being highlighted. "Food and Immigration. The indigestion trope contests the sophistication narrative" sheds some light onto how foreign influences are perceived as a threat at the same time that challenges of integration into mainstream culture are chaneled through the culinary metaphor of the immigrant as a poisonous foodstuff.

On other occasions images of food are used with the purpose of inclusion and assimilation. This is particularly clear in countries whose make-up is the product of several waves of immigration (see Lehrer 1990). In such cases a dish made of several ingredients is picked out in order to convey the idea of inclusion. Consider, for example, the South-American countries of Cuba and Chile, whose present population is a mixture of people since the Discovery of America in 1492. The Caribbean island is frequently imagined as an ajiaco (see Galván Tudela 1998), a kind of

20 This is the metaphor of the BODY POLITIC (see Harvey 2007). 
stew made of several ingredients whereas Chile is seen as an empanada (see Holahan 2002), that is, a pie, since this is a type of pastry also filled with different ingredients.

But perhaps nowhere is the connection between food and patriotism made more obvious than in the series of culinary metaphors with which the USA tends to be referred to. The country par excellence associated with immigration, America has forged its national identity by bringing different cultures together. Such multiculturalism was originally seen with the metaphor of the melting pot which revolves around the analogy that the ingredients in the pot (people of different cultures and religions) are combined so as to lose their discrete identities and yield a final product of uniform consistency and flavour, which is quite different from the original inputs (see Gloor 2005:29).

Yet, because the idea of cultural diversity seemed to be lost in such a metaphor, the melting pot has been gradually abandoned in favor of other culinary metaphors like the salad bowl and more recently the tomato soup or the ethnic stew (see Gloor 2005) in which the different ingredients, that is, cultures, retain their flavors, in other words, identities, and contribute to a rich and delicious meal or to a rich and diverse country.

The connection between foods with national or ethnic groups does not end here, however, and the reverse phenomenon is also seen at work. That is, real foodstuffs are also given the name of different ethnic groups. There are examples galore of products which harbor ethnic images and in so doing reinforce stereotypes. To illustrate this point one should consider the names given to round-shaped chocolate sweets in several countries: Mohrenkopf ('Moor's head') in Switzerland, tête de nègre ('Negro's head') in France and Belgium, Negerkuss ('kiss of blacks') in Germany or morenitos ('dark skinned') and conguitos ('people from Congo') in Spain. Certainly, the shape of the product together with its appearance seems to motivate the image, but the identification between such bakery products and black people is not only based on visual grounds; on the contrary, as research has shown (see Bendix 1993), racial overtones are also conveyed, which are often reinforced by marketing strategies given that such products tend to be accompanied by stereotypical images of black people, where blacks are depicted with exaggerated physical traits of thick lips and as savages with virtually no clothes and carrying spears.

In this regard, as will be seen later on, it is interesting to notice how stereotypical images of ethnic groups used in the marketing of some products have made their way into language in the form of food-related metaphors. As an example, consider the man Juan Valdez from the Colombian coffee brand or the well-known black couple of Aunt Jamima and Uncle Ben used to advertise breakfast and comfort foods. Such names are today synonymous with Colombian and African-American people respectively.

Most obvious derogatory coinages can be seen in slang. In the army in Switzerland poor quality food is often associated with Jews and Blacks, groups which, historically speaking, have been looked down on. So gstampfte Jud, literally 'mashed Jew', stands for tinned meat whereas Negerschweiss, that is, 'negro's sweat' or 'negro's syrup' refers to cocoa, coffee or tea. Such expressions, according to Bendix, associate "the generally poor quality of military food with a faulty perception of Black physiology" (ibd. 1993:17). 


\section{Food based metaphors and "the other"}

Hatred towards strangers appears to be an ingrained feeling almost from the dawn of times. The issue of racism has a long tradition (see Fredrickson 2009). People may see race as an extension of the family and have loyalties to their own as they would to their own family, tribe, clan or nation. The concept of racism may have originated as an extension of feelings of loyalty towards the family. This in-group membership often translates into a distrust and dislike of out-groups (i. e. groups or communities that are distinct from one's own). In fact, members of other groups tend to be seen with disdain due to the fact that they speak unfamiliar languages, wear different clothes, have other customs and eat distinct foods, which can lead to distrust and even contempt. Furthermore, historically speaking, military invasion, religious rivalry or economic competition between various groups may likewise give rise to resentment, disdain and even hatred. ${ }^{21}$

Aversion towards other groups or communities is often materialized in language through metaphor. By focusing on differences metaphors may distort the target's group identity. The main areas of distortion on which metaphors are based include, but are not restricted to: traditionally attributed names (e. g. the Russians call the Germans Fritz, which is short for 'Friedrich', a very common name for Kaisers), physical characteristics (e. g. in Spanish cabezas cuadradras, that is, 'square heads', refers to the Germans), occupational stereotypes (e. g. in American English Hispanics are often seen as berry-pickers for they tend to work berry fields in California), animals (e. g. Danish people call Norwegians fjeld abe, that is, 'mountain monkey'), stereotypes of low intelligence (e. g. blacks are seen as hard-heads in American English), status diminution (e. g. in Peninsular Spanish chamaco, literally denoting 'boy' or 'child', applies to the South Americans), colors (e. g. 백 baek or white used with 인 in to make 백인 literally means 'whiteperson' in Korean) and clothes (e. g. Hungarians call Austrians labanc in reference to the clothing worn by Austrian troops during the Hungarian war for independence) and, last but not least, as this paper will try to show, distinctive food (e. g. in Hebrew Italians are called loksh or 'noodle'). ${ }^{22}$

Of all the differences that exist among human beings, food is, perhaps, the most noticeable feature setting people apart, given that it fulfills a basic biological need and, therefore, it appeals to the senses, in other words, to primary instincts. Besides, because food choices vary across cultures, foodstuffs comprise the biological and the social and, therefore, become strong markers of identity. Different gastronomies have always caught people's attention, not only in times of the first colonial encounters but also in present day society, judging from the proliferation of international restaurants, books, cooking courses and the aisles of supermarkets which display a wide variety of the so-called exotic products brought from all over the world. Yet, just as food

\footnotetext{
21 In this regard Hughes (1991: 5) points out: "Since xenophobia, or hatred of strangers, is a feature of most societies, terms for aliens tend to form a notable word stock in the vocabulary of swearing and vituperation. Various stereotypical behaviors are attributed to aliens. These include barbarism, savagery, sexual perversion, paganism, stupidity, lack of hygiene, dishonesty, unscrupulous business practices, strange clothes and eating habits, inarticulateness, and incompetence in using the speaker's language. These present various degrees of threat to the "home" culture, which stigmatizes outsiders accordingly. Thus terms like macaroni, frog and limey derive from fairly trivial notions or myths about diet, whereas the derogatory use of jew in phrases like to jew down, meaning "to cheat," is a far more profound criticism. The prime forces driving the early generation of xenophobic attitudes are religious and martial rivalry."

22 This classification was put forward by Hughes (1991).
} 
serves to draw boundaries between different groups, it can also be employed to blur those distinctive lines and bring people together. ${ }^{23}$ Actually, knowledge of other cultures is often gained through our stomachs and the cuisines of many countries are the clearest testimony of our multicultural past, with dishes which mingle the ingredients and flavors of different ethnic groups.

What follows now is a classification of food-based metaphors used in the conceptualization of different ethnic groups in English. Needless to say, the categories established are not clear-cut and, as will be seen, often overlap; yet, they serve obvious methodological purposes. Briefly put, in the course of this research, the food-related metaphors with which different groups tend to be identified seem to be motivated by the following factors:

1) Typical/staple foods in the diet

2) Based on physical grounds:

a. Colors

b. Shape

3) Based on the state of food

4) Based on brand names of food

5) Based on jobs connected with food

6) Based on food for animals

7) Based on historical grounds

8) Based on acoustic considerations

\subsection{Typical/staple food in the diet}

The food typical of the diet of a group stands for the people who eat it. This is a case of metonymy in which an element stands for a phenomenon to which it has any degree of association. Metonymy, then, unlike metaphor, involves mappings between entities that belong to the same domain. The food chosen to represent a particular group tends to fall into two main categories. On the one hand, there are foodstuffs which are part and parcel of the diet of an ethnic group, such as sushi in Japan or beans in Mexico, and, on the other hand, there are foods which are seen with disgust by the community that coins the metonymy, like the well-known frogs to refer to the French.

The French are seen as cheese-eaters, baguette-eaters, croutons, butterfingers and the bestknown historically speaking frogs and toads. In the same line, Canadians, apart from being represented by their national cuisine in the guise of poutine, maple-sucker or pea-soup, bear witness to their French heritage in the frog-derived metaphors frozen frogs and bay frogs. The former makes reference to the freezing temperatures of the country whereas the latter is heard in the Hudson Bay area where the French-and English-speaking communities co-exist.

\footnotetext{
${ }^{23}$ Food has this dual and antithetical function of exclusion and inclusion: "Food can be employed to draw borders and create distinctions between "us" and "others," or it can serve as a tool for bringing together people with diverse background and as an instrument of unification" (Bell/Gill 1997: 168-169).
} 
Within the European borderlands, the British are called roastbeefs and beef-eaters, tea-bags and tea sippers and even crumpet-suckers. Irish are seen as potato-eaters and Guiness-drinkers whereas the Scots are commonly referred to as porridge dribbler, porridge wog, haggis muncher or ginger baws. The Belgians tend to be seen as cheese-eaters and waffles; the Dutch are also cheese-eaters; the Danish are butter cookies, Norwegians fish-eaters or salmon-eaters; the Italians are bread, meatballs, garlic and different types of pasta such as calzone or macaroni; the Greeks are yoghourts and lamb chops and the Germans are sausage-munchers and kraut (short from sauerkraut).

From Asia two main ingredients appear to stand out from its cuisine, namely, the staple rice and the seemingly revolving insects in the eyes of most Westeners and, therefore, the metaphors rice-eaters, rice balls and bug or insect-eaters. Other culinary terms include soy sauce and egg rolls. Distinctions are sometimes made among the different gastronomic traditions of each country. Such are the cases of sushi-eaters for Japanese people, (fortune) cookies and dim sum for Chinese and dog-eaters or dog-munchers for Koreans and Vietnamese. In addition, the love for spices of Indians certainly accounts for the figurative usages of curry, curry-muncher, curryslurper and the more pejorative curry-stinker to refer to this nationality. Similarly, the wide variety of dried fruits and nuts of some Middle-East countries pave the way for the metaphors fig and nut gobblers. Interestingly, just like in the Canadian case of frog-derived metaphors, geographical features also play a role in the coinage of food-based metaphors, as seen from dusty nuts in allusion to Arabs - the dust being typical of the desert. Australians and New Zealanders can be conceptualized in the form of can-eaters and kiwis, respectively. The first alludes to the amount of canned beer that they consume and the second to the autoctonous fruit. ${ }^{24}$

America displays the most extensive menu, probably because it is a large continent forged by immigrants. Native Americans are maize-munchers and gut-eaters for they tend to eat the stomach of deer, buffalo and other animals. Whites descendants of Europeans are hot-dog and hamburger munchers whereas African-Americans are conceptualized as (water)melons, melons or chicken eaters. The Jews are also the target because of their eating practices due to religious beliefs. So Kosher or Kosher-eaters, kosher-sausage together with other products such as noodle soup-eaters or different sorts of bread which include bagel, bagel dog, matzah, or bun are used to refer to this group. Curiously, the forbidden pork also finds its way into language since this meat is applied to the Jewish community in America, particularly porky.

Maybe the most fruitful domain in terms of foodstuffs comes from Hispanics, which is not surprising taking into account that they constitute the fastest growing minority within the USA. Staple foods of their diet are transferred to the people who consume them. For instance, taco, tamale, chalupa, burrito, nacho, chilli or corn, to mention a few, are figuratively used to refer to this group. However, despite the variety of the aforementioned foods in South, Central America and Mexico, beans appear to have a prominent place in terms of their diet and therefore in terms of their identity. As a matter of fact, bean is in all likelihood the most common metaphor used in the identification of Hispanics, as seen in its widespread use as well as in the word formation processes this term has undergone. So by means of affixation bean has generated beaner ('a Hispanic person') and beanies (the diminutive explains its use because Hispanics,

${ }^{24}$ The case of Kiwi is an example of folk etymology given that originally the term refers to the bird, not the fruit. Yet, it is possible that today's speakers associate this word with the food as well. 
apart from eating beans, tend to be of a short height) whereas the blend of beans and Spaniard results in Beaniard, that is, 'a person of mixed background'.

The metaphor bean has caught on in language to such an extent that it has generated a whole network of spin-offs. So, the stereotypical image of Hispanics as thieves is channelled through bean bandits whereas non-Hispanics who date Hispanics become bean-dipers. In addition, beans come in different colors: black beans (black Hispanics), green beans (Irish Hispanics) and white or pinto beans (white Hispanics), tastes: black jelly beans (black people), coffee beans (Colombians); packages, given that bean bag and bean ball are synonymous with Hispanics, and provenance because island beaner alludes to Cubans whereas jumping beans evoke those Hispanics who leave their homelands and attempt to enter the USA by jumping over fences.

\subsection{Metaphors based on physical grounds: color and shape}

Another set of metaphors for ethnicity stems from visual grounds. In order to come to terms with people who eat and look differently, the color and shape of foodstuffs have always been at hand. Color terminology has been used since the dawn of times to create a taxonomy of human races because of the glaringly obvious differences in skin colors. Hence it seems logical that the color of certain foods be used to conceptualize human groups. Traditionally five races have been distinguished based on their melanin, that is, black, brown, red, white and yellow, which runs parallel to the figurative use of products which display those or similar colors, such as chocolate, cinnamon, cherries, flour or lemons, respectively.

Yellowish foods for Asians include yolk and butterheads (Japanese only). The reddish appearance of apple and raddish match the skin color of native Americans and so does a wide repertoire of white foods like bacon bits, marshmallows, mayo(nnaise), milkhead, whitebread, cracker, yoghourt or flour bag to denote the white man. Special attention should be paid to cracker and its derivations. ${ }^{25}$ In fact, not only does cracker along with its spin-offs reveal belonging to a race based on the skin color but also social status. This thin crisp baked bread was originally used for poor white southerners in the US. Because this product is relatively cheap, despite its whitish appearance, two other types of cracker of different prices have been used to refer to middle class (saltine) and upper-class (Ritz) white people. In accordance with skin color, when dealing with blacks and Hispanics, burnt cracket and the brand Trisket (multi-grain cracker) are chosen. Finally, as for mixed races, the assortment includes rice crackers ('Japanese and whites'), Graham crackers ('whites and Hispanics'), spicy crackers ('Mexicans and

\footnotetext{
25 Etymologically, the word cracker derives from Latin crepare, meaning 'to rattle, crack, creak' (O.E.D.). The association with the thin crispy baked bread clearly suggests an onomatopoeia. Yet, the meaning of cracker to denote a 'poor Southern white' is controversial and there are several theories trying to account for the human sense. Within the onomatopoeic connection one hypothesis links the human reference of cracker to the cracking sound of whips either by masters in antebellum America or by rustics guiding their cattle. Those white foremen or rural people became known as crackers. Another whip-derived theory can be traced back to cowboys in Florida. These men used whips instead of lassos to herd or capture cattle and soon were called cracker cowboys. There is also a food-related theory linking crackers with the common diet of poor whites in the Southern states of the U.S.A. Apparently, the human sense of "cracker" might have been derived from the cracked kernels of corn, which formed the staple food of low-class people. Whatever the origin, however, it seems clear that the metaphorical network woven around cracker lies in its edible sense.
} 
whites') and soggy crackers ('Mexicans and whites'). This last metaphor instead of being motivated by the color of the cracker is rooted in its consistency and evokes the metonymy of the "wetbacks" with which Hispanics are referred to because many attempt to enter the USA by swimming.

For black people chocolate and its varieties seem to be the best form of expression to go with their skin color. Together with the basic ingredient cocoa, chocolate and its apocope choco are metaphorically used to refer to blacks. In fact, as seen before, there is a whole network of subproducts based on chocolate to denote people who are either black or have any kind of connection with this race. So, for example, there exists a wealth of brand names of chocolate to refer to blacks, such as Frogs, Freddo, Malteesen or Hershey. By the same token, those whose skin color is really dark are referred to as double dip chocolate whereas those who have a lighter complexion are labelled as white chocolate. If black people are metaphorically conceptualized as chocolate, it seems logical that chocolate drops and cocoa puffs be applied to black kids, the metaphor being coined on the grounds of small size. In like manner, chocolate products are at hand when dealing with people of mixed races or who adhere to a lifestyle typically associated with the black race. Consider, for instance, brownie, denoting someone of Hispanic and black origin due to the color of this sponge cake or the well-known brands Oreo and Bounty bar, which can denote either people with white and black ancestry or simply people who act black, given that these sweets are made of white chocolate covered with dark one. Other common metaphors referring to white people who act black include white chocolate and chocolate-covered marshmallow.

Nonetheless, chromatism seems to play such an important role in defining how people view one another that there is a whole repertoire of tone hues and gradations in the foods selected. As reflected in the metaphorical network, darker-skinned blacks are distinguished from lighter ones and so the existence of the metaphorical dark and white chocolate and even caramel one. Similar consideration apply to the previously studied bean network in which different colors of beans (green, black, pinto or brown) specifically represented different people based on colors.

Moreover, there are further subdivisions within the traditional races based on skin colors. The color spectrum comes into play with carrot or ginger to refer to the typical red-haired Irish whereas Arabs are visualized in terms of latte, mocha and even peanut butter owing to their brownish complexion.

Sometimes, however, the names of ethnic groups may contain colors which do not indicate skin color but rather their identification lies in traditional clothing, historical or geographical reasons. Going back to the bean metaphorical network the connection between green beans with people from Irish and Hispanic ancestry comes from the fact that green is the color associated with Ireland because of its flag and landscape. Likewise, the Dutch are labeled as orange heads or simply orange and so are Protestants living in Northern Ireland. Here the motivation has to do with the lineage of the current dynasty of The Netherlands, the House of Oranje-Nassau.

Interestingly, sensitivity to gradations of skin tone and, after all, to the mixture of races is conveyed by means of the colors of certain foods. There seems to be a tendency towards stigmatization of interracial relations and adaptation to other cultures. Betrayal to one's identity, symbolically represented in food colors, is materialized in edible substances which have a color 
outside and a different one inside. Conspicuous examples include banana, coconut, potato and egg. Being yellow on the outside, bananas seem to correspond with the skin color of Asians. Yet, this fruit is applied to an Asian person living in a Western country given that after removing its peel bananas are white. By the same token, bruised bananas are employed for Asians who are fond of black culture. In like manner, eggs present the yolk and the white, which accounts for its metaphoric sense to refer to white males that are into Asian culture. Hispanics who have been assimilated into white culture are accused of being potatoes and coconuts. The metaphor resides in the brownish skin and the white inside. Coconuts are also the metaphors used in the USA for a black person and in New Zealand and Australia for a Pacific Islander who adheres to white culture.

Further examples of deceptive appearance hinted by the colors of food abound in the sweet section. As stated before in the chocolate network, bounty bar, oreo and chocolate-covered marshmallow are racial slurs in the USA to name blacks who seem to share the cultural values of white people who, in turn, are conceptualized in the form of white chocolate when trying to sympathize with black culture. Also the sponge cake twinkie refers to Asian-Americans who seem to have lost their heritage since once again they are yellow on the outside but white on the inside.

As far as mixed races are concerned, there are also examples galore of products whose either their colored appearance or their ingredients suggest the idea of interracial relations. Apart from the examples already analyzed, there are California rolls for Asian Americans, burnt rice for dark-skinned Asians, meat pies for white Hispanics and cheese nip for whites and Japanese.

Continuing with visually motivated metaphors, another set of food items revolves around shape. Some ethnic groups are characterized by their small height and that is why foods of small size are used in their identification. For instance, Asians have a reputation for being relatively short in comparison to other races and that is why pip, that is, the small seed of a fruit, is used to refer to Japanese. On other occasions characteristic physical traits are highlighted to strengthen physical differences. So the flattened face of Asians and Eskimos with their snub nose is rendered into pancake face or pieface - notice that in the first metaphor the yellow color of the food also works with the skin color of the race. Salient physical traits are highlighted in biscuit lip or biscuit head. The former refers to the thick lips of black people; the latter to the head of Koreans. Even hairstyles become the object of derision, as seen in muffin head to designate Afro-style.

\subsection{Metaphors based on the state of foods}

Foods can be eaten raw or cooked in a variety of ways (i. e. boiled, baked, fried, steamed, etc.). They can be consumed when they are green or ripe and even when they have gone off. All these different ways of food state, preparation and consumption have become grounds for the metaphorical conceptualization of different ethnic groups.

Generally, when uncooked, foods tend to have a lighter appearance, which accounts for the use of raw to refer to white people. By the same token, the darker complexions of other races like Hispanics, Native-Americans and obviously blacks have led to their identification in the guise of cooking processes such as baked, roasted, (deep)fried and burned. 
Interestingly, when such cooking processes have not been completed, metaphors for mixed races emerge. So half-cooked and half-baked refer to mixed people, usually blacks and whites. In like manner, losing one's identity because of contact with other cultures is materialized in the metaphoric uses of pocho, the Chicano derogatory term referring to Hispanics who cannot speak Spanish, and rotten, as shown in the collocations rotten banana ('an Asian person who sympathizes with black culture'), rotten coconut ('Hispanics who lose their heritage because of assimilation into white culture').

Less transparent figurative senses based on historical facts include baked, smoked and crunchy. The former applies to the Jews because of the practice of burning Jews during Holocaust whereas the latter pertains to US military slang since it was used by marines in the second Iraq war to refer to dead Iraqis when killed with tanks because of the sound made by the bodies when crashing.

\subsection{Metaphors based on brand names}

An all-pervasive metonymy within the food domain is THE NAME FOR PRODUCT. This common phenomenon takes place when a brand name becomes generic and replaces the names of other products. Very often consumers take a popular or a top-of-mind example of a product and use it to encompass other products within the same category. For example, when making a shopping list or ordering some soda, the trademark Coca-cola is usually at hand regardless of the real brand actually consumed. Needless to say, this is one of the main goals in advertising and hence marketing strategies play a pivotal role not only in terms of creating a trademark, but also when it comes to designing the logo or coming up with a motto, since the failure or success of the product will largely depend on the advertising campaign.

Because ethnic and national groups are often portrayed in the guise of foods, brands are likewise used in their conceptualization. Popular trademarks used in the identification of ethnic groups include Goya and Trisket for Hispanics; KFC for African-Americans; Dr.Pepper or Pepsi for French Canadians and Ritz for US whites.

The association of the soda names Dr. Pepper and Pepsi for French Canadians seems to be derived from the Anglo-Canadian jibe that their stereotypically bad dental hygiene was due to drinking large amounts of these drinks. As for $K F C$ the connection with the African-American community is crystal clear, as seen in the previous metaphor chicken-eaters, because this group has a reputation for loving fried chicken, particularly in the southern states of the USA. In terms of Hispanics, Goya is perhaps the most popular brand and most mainstream Latin food company around the world, which explains its metonymic use to identify this group. The brand names for crackers Trisket and Ritz to represent Hispanics and rich white people in the US have already been analyzed and were based on the color of the ingredients together with the price of those brands (economical multigrain cracker in the case of Hispanics and more expensive white one for the whites).

Interestingly, there is a set of brands that metonymically stand for a specific ethnic group not only because of their name itself but also due to the image with which they advertise the product. Not surprisingly, the image used in the packages reinforce stereotypical views of ethnic groups by playing with physical distortions or with traditionally attributed jobs. Needless to 
say, pictorial elements in advertising are crucial in terms of mnemonics, for, after all, an image is worth one thousand words. At the same time such visual component might facilitate the coinage of the metonymic use of the brand due to the very functioning of metaphoric processes, since most of them involve mental imagery.

Advertising is rife with stereotypical images of national or ethnic groups and the food section is no exception. Common examples that come up to our minds include Lucky the Leprechaun with his shamrocks and Irish brogue from the Lucky Charm breakfast cereal or Frito Bandito, the Latino rascal who carries a pistol and a perchant for stealing chips and is clad in a huge sombrero and boots with spurs for Frito-Lay corn chips. On many occasions the images used to market the products catch on so much so that they become synonymous with the group portrayed and metonymically stand for them. Such are the cases of the well-known African American couple Aunt Jemima and Uncle Ben; the Colombian coffee collector Juan Valdez along with the Latino bomshell Chiquita banana; the Eskimo pies for those of the same name and Camel Crunch captain for the Arabs.

The name Juan Valdez owes its existence to the man that appears on the cans and packages of Colombian coffee. Although at first sight the image might evoke a bucolic and traditional way of coffee production since there are some mountains in the background and the man is dressed with a traditional rural attire with the big hat and saddlebags where the coffee beans can be left and accompanied by a donkey, hinting at the idea of hand-made and natural processes, one can also notice how physical features typical of Colombians are exaggerated. Attention should be drawn to the bushy moustache and sideburns together with the dark-skinned complexion. In like manner, the sticker of the bananas Chiquita displays a bomshell Latin American woman who wears a fruit-laden hat and a ruffled skirt. ${ }^{26}$ Apart from suggesting the idea of tropical and freshness of the fruit, the image is overtly sexual.

Physical features are, no doubt, distorted in the African-American couple of Aunt Jemima and Uncle Ben. She is the typical mammy character with grossly exaggerated features such as very thick lips, which reminds one that biscuit lip and sausage lip are figuratively used for AfricanAmericans, as already stated, curly hair, pearly teeth and high cheek bones whereas her male counterpart is a cheerful and friendly butler and cook. Despite the fact that Uncle Ben is not portrayed with exaggerated physical traits, the idea of servitude is likewise conveyed for both charaters make a living serving people. Finally, the forms of address Aunt and Uncle are reminiscent of segregation times because they derive from the practice of whites addressing elderly African-Americans, as opposed to the titles Mr. and Mrs., which were deemed unsuitable for blacks, and only used within white circles (see Wilson/Gutierrez/Chao 2012).

Eskimo pie ice cream bars also resort to the image of an Inuit boy in a parka for marketing purposes. Certainly Eskimos live in cold climates and therefore they seem an appropriate image to advertise ice-creams and frozen meals. Yet, as seen before, there seems to be a tendency towards poking fun at the physical traits of Eskimos, which, as already said, explains the metaphors pieface and pancake face to refer to them because of their snubbed nose and flattened face. In fact, in the package there is a smiling boy whose portrayal is exclusively limited to his face.

26 The image supposedly is based on Latin actress Carmen Miranda. 


\subsection{Metaphors based on jobs involving food}

It goes without saying that along with the foods consumed jobs are likewise important markers of social status. An individual is often valued by the position he holds and there are metonymies galore based on jobs. An instrument or tool may stand for the person using it (e. g. racket for tennis player or pen for writer) just like the uniform or clothes traditionally worn to work (e. g. white-collar vs blue-collar workers). The name of an organization can represent its members, particularly the spokesperson (e. g. BP announced several lay-offs); an emblematic building where people work may stand for the workers themselves (e. g. The White House will make an announcement soon) and a position may be used to stand for the person performing the job (e. g. the chairman, the throne).

There is a set of ethnic slurs commingling foods with jobs connected with food collection and preparation. Hispanics are often called berry-pickers, cherry-pickers, fruit-pickers, orangepickers or tomato-pickers for they are usually the ones who collect these fruits in the USA. In like manner, the second largest minority within the USA, African-Americans, is called cornpickers. Similarly, wine production tends to be associated with French and Italians, who are conceptualized as grape-stompers and grape-smashers whereas the Greeks and Asians are linked with oil and rice production and so olive-pickers and rice-pickers.

Curiously, all of the terms used in the conceptualization of these groups involve physical work rather than intellectual; likening these national groups to machines or even animals, metaphors, which, by the way, pervade immigration discourse and have traditionally been used to justify oppression.

On other occasions one comes across places where foods are traditionally sold in order to stand for a particular group. This is the case of beef curtains for the Greeks, spaghetti vender for Italians or tortilla curtains for Mexicans. Dehumanization is more obvious in these instances in which these nationalities are reduced to objects, hinting again at the metaphor IMMIGRANTS ARE MACHINES.

\subsection{Metaphors based on food for animals}

Although the choice of substances which are regarded as edible or non-edible is culture specific, there are some foodstuffs which are just reserved to animals, either to feed them (like fodder) or to hunt/catch them (like bait). Needless to say, if comparing people to food was already degrading within the cultural framework of THE GREAT CHAIN OF BEING, their identification with products given to animals is even more humiliating since the animal realm in being highlighted, with the instinctual qualities of brutality, lack of reason and servitude to men attached to it. Certainly, as said before, such attributes prove useful in order to support racist ideas on the superiority of certain groups and to justify oppression and inhumane labor conditions.

Belonging to the category of foodstuffs for animals, one comes across alligator bait in reference to African-Americans, especially children. The origin of this metaphor goes back to the practice of using little black children as bait to catch alligators in southern USA in the time of slavery. Another common metaphor is fodder, with which horses and other farm animals tend to be fed. Maybe it is this rural ambience which has motivated its figurative meaning to denote farmers 
in the USA. Other variants of this metaphor include twister fodder in reference to Midwesterners due to the fact that this area is prone to tornados and fodder beet, the red root vegetable fed to livestock whose color has prompted its sense of rural Native Americans.

\subsection{Metaphors based on historical grounds}

To begin with, a note should be made regarding the title of this section, which may seem misleading given that all food-based metaphors have been coined at one point in history and, therefore, context is pivotal to decipher their motivation. In fact, as has been seen, there is a wide repertoire of factors (i. e. eating habits, religious practices or beliefs, shape, color, texture, brand names) which account for the identification of ethnic or national groups with foodstuffs. Yet, it cannot be denied that whereas it is relatively easy to understand the identification between the figurative chocolate with black people, the connection between the very same group with apples is a priori not so obvious since neither the physical appearance of the fruit nor eating or religious customs play any kind of role in the forging of the metaphor and it is only by adopting a diachronic approach which goes back to the practice of lynching that the underlying assumptions can be retrieved. In other words, there is a set of metaphors like chocolate which may be labeled as transparent because their figurative meaning can be retrieved from a synchronic point of view. On the contrary, metaphors like apple are termed as opaque because their understanding necessarily involves knowledge of history. This part, then, focuses on these opaque metaphors which require historical grounds to unveil their motivations.

Some common terms with which African-Americans are often associated include fruit, strange fruit and apple. These metaphors can be traced back to the practice of lynching blacks in the USA since many blacks were hanged from trees as a punishment. So the visual connection between a black and a fruit hanging from a tree was established and fruit became a euphemism to refer to blacks. Later, because the default fruit is the apple such a word acquired the same figurative sense as fruit. Finally, strange fruit, although also based on the image of lynching, comes from the title of a jazz song by Billie Holiday (Fruit of the gibbet) whose lyrics dealt with a hanged man.

A similar provenance is seen in the metaphor candy man, which owes its existence to Sammy Davis Jr.'s famous song The Candy Man. Although there is no explicit mention to black people in the lyrics, the fact that the song was sung by a black singer and that it is part of the soundtrack of the movie Willy Wonka and the Chocolate Factory seems to hint at the visual metaphor that identifies blacks with chocolate products due to the similarities in terms of color.

From military slang comes cookie. Some sweet metaphors were previously analyzed but in those instances the metaphor was coined on visual grounds, namely, on the color of the ingredients used, but in this case it has to do with job practices. In fact, one of the very few jobs that blacks were allowed to do after enlisting in the US navy was food preparation. Finally, there is the traditional dish called Hoppin' John which was eaten by black slaves and became associated with this race and even today it is synonymous with black people.

Naval practices required British sailors to consume lime juice as a beverage to prevent scurvy. Hence the metaphors lime-juicer, lime or limey were forged in the $19^{\text {th }}$ century. Eventually, the 
metaphors lost their naval connection and were used to denote British people in general. Later on they were used to refer to English immigrants in Australia, New Zealand and South Africa.

Rivalry with their Irish neighbors led the British to focus on differences to draw not only physical boundaries but also identity ones. Religion has traditionally separated those nations and British Protestants targeted Irish Catholics by focusing on their dietary practices, hence mackerel snapper was born. The metaphor originally applied to Irish Catholics because due to their religious beliefs they were forbidden from eating meat on Fridays during Lent and mackerel was one of the most consumed fish.

Like in the case of the figurative apple, cruel practices dating back to Nazi Germany also account for many of the food-related metaphors applied to Jews. Some of the horrible practices of extermination in concentration camps revolved around the burning of Jewish people, which explains the whole repertoire of foods that need to be cooked in the oven, such as hot pockets or pizza and bakery products like buns or gingerbread man.

\subsection{Metaphors based on acoustic considerations}

Contrary to the Saussearean view on the arbitrariness of the linguistic sign, the relationship between the signifier and the signified is often motivated In fact, research has shown that metaphor and metonymy are crucial mechanisms accounting for semantic extension (see Taylor 2003: 643). The different but related senses of polysemous terms are often explained thanks to relationships of similarity (i. e. metaphor) and contiguity (i. e. metonymy). As this paper has tried to show, the primary, more concrete meaning of the names of many foodstuffs has extended its literal sense of edible substance to denote different ethnic groups. Sometimes, visual similitude like color or shape has given way to the figurative senses of chocolate and lemon to refer to blacks and Asians respectively or pie-face for Eskimos (metaphor). On other occasions a staple food eaten by a specific community or a job involving food and traditionally performed by a group stands for the community itself (metonymy), like the uses of baguette-eaters for the French, curry-munchers for the Indians or berry-pickers and grape smashers for Hispanics and Italians.

Along with metaphor and metonymy, phonetic considerations also play an important role in the coinage of ethnic slurs. As a matter of fact, playing with sound relations is a common device in the creation of terms which disparage out-groups. Many of the sexist and homophobic metaphors pervading daily speech have been prompted by sound relations. By way of illustration, consider the commonplace chick denoting 'a young woman', which has generated spin-offs such as chick flick ('a movie targeted at women') or chick flick fodder ('material to produce films for females') (see López-Rodríguez 2009). Metaphors applied to the gay community equally rely on acoustic motivation, like chunder plunder, muff buffer or todger dodger, among many others, and so do those words conveying xenophobic views (see Lillo 2001), like in bubble and squeak in reference to a Greek, box of glue instead of Jew or grave digger for nigger.

This phenomenon of coining new words with rhyming patterns is highly productive in the field of stereotypes. Certainly, beneath apparently catchy terms lie negative views against less powerful social groups. In fact, according to Lillo (2001: 337-33), this type of word formation process manages to hide the target word behind the false front of rhyme and at the same time 
suggest disparagement and downgrade the target's group identity by occasionally exploiting figurative interpretation and sound-sense relationships.

In the field of foodstuffs related to ethnicity sound patterns are also exploited. There are some cases in which the gentilic is similar in terms of spelling and/or pronunciation to the name of the food. The first case that comes up to mind is the very word immigrant, whose sound and graphic similarity hint at the fruit pomegranate or its contracted diminutive versions pommy, pommie or pom, used to denote an English immigrant in Australia, New Zealand and South Africa. ${ }^{27}$ Other examples include the Turks, who are called turkey sandwich; the Poles, named rolls or the Guatemalans, watermelons.

In other instances, compounds evoke the spelling and pronunciation of the target group, like in pork cheese ('Portuguese') or the opposite phenomenon, that is, a blend condenses the idea of two groups, like in vinegar, which stands for the mixture of Vietnamese with nigger or cashew, condensing the religious groups of Catholics and Jews.

Less transparent two- and three-word structures revolving around food imagery include lemonade spade and egg and spoon ('a black person'), mutton shanks ('North Americans'), tea for two ('Jew'), rice and sago ('Greek'), oil slick ('Hispanic') or luger lout ('German'). Lemonade rhymes with spade, the black figure on playing cards which metaphorically refers to blacks whereas egg and spoon suggest coon, another offensive term for people of the same race. Mutton shanks evokes Yanks, abbreviated form of Yankee, referring to a white person from the US whereas the phonetic sequence of tea for two suggests Teafer, which in British slang means 'Jew'. ${ }^{28}$

In the same fashion, rice and sago point to dago, from the Spanish proper name Diego and, by extension, applied to Mediterranean people whereas the derogative spic, a play on the pronunciation of Hispanics when trying to speak English, is camouflaged with the compound oil slick, alluding to the belief that Hispanics are oily or greasy, just like their food. Another culinary pun is found in the compound luger lout, whose second constituent rhymes with kraut, a traditional food of the German cuisine.

This playful dimension is also at work with prototypical names. As was mentioned before, traditionally attributed names become frequent invectives to attack outsiders. Common names like Fritz, Abbie, Mick or Pat globally stand for the Germans, Jews and Irish. A similar tendency has been observed with family names in relation to foods. One of the most typical last names for the Scots and Irish is $M(a)_{c}$-, which coincides with the first letters of a well-known chain of fast food, MacDonalds. That is why Mc-chicken alludes to the people from these nations and, logically, McNuggets refer to their children, given that the nuggets are the small parts of a chicken. A similar wordplay can be observed with mixed relationships. Hence, Irish and German couples and descendants are identified as McKraut. As for the Jewish, the suffixes -burg/berg are very typical in their last names. Because of phonetic similarity, hamburger or its clipping burger are employed to refer to this community.

\footnotetext{
27 This usage of pomegranate may have been strengthened by the belief in Australia that sunburn was more common among English immigrants, turning their fair skin color into red, just like this fruit. Besides, there are some folk etymologies suggesting that pom and pome are acronyms that stand for 'prisoner of mother England' (POME), 'prisoner of millbank' (POME) or 'prisoner of her Majesty's service' (POHME).

28 I am indebted to Lillo (2001) for all these examples.
} 


\section{$7 \quad$ Discussion: Food-based metaphors \& racism}

Metaphor is one of the main mechanisms that contribute to the diffusion and ingraining of folk beliefs. Through metaphors people express a picture of reality or a world view. In fact, most metaphors are not neutral in their evaluative stance (see Nunberg/Sag/Watson 1994; Moon 1998), but are charged with an ideological or attitudinal component (see Fernando 1996) which reflects a bias on the part of a community towards other groups of peoples, mores, situations and events. The attitudes conveyed by means of metaphors originate in what is known as general or universal knowledge, in other words, conventional views attached to the cultural values held by a community (see Deignan 2003; Maalej 2004). This communal voice condensed by metaphors is frequently used by speakers as arguments of authority to validate or sanction particular behaviors (see Drew/Holt 1998; Moon 1998). Seen in this light, metaphors may become covert means of transmitting and perpetuating certain norms for the benefit of a particular community (see MacArthur 2005).

Metaphors offer a window on the construction of identities. Being channels of folk beliefs, many metaphors convey biases in favor of particular groups that are considered as the normative in detriment to those individuals who do not conform to this group. Ethnic metaphors against supposedly inferior groups linguistically marginalize people based on differences - be they language, clothes, color of skin or, as this paper has tried to show, food habits - while conveying the fears, usually of the white man, against the new people encountered or the newly arriving immigrants.

It is by targeting those differences that individual as well as collective identities are constructed. In fact, in the forging of identity dualisms seem to play a pivotal role and a person's own definition in terms of group membership entails the identification of that person with the norms, attitudes, beliefs and behavior of the in-group, which, in turn, will be constructed in a constant dialectical process of opposition with the out-group. To put it simply, similarities among different human groups are disregarded in the fashion of identities whereas differences that separate people are enhanced.

In the case of food-based metaphors different culinary traditions serve to set people apart, increasing, therefore, the gap between the us and the others, for, to put it in Altman's (1990: 502) words,

Metaphors [...] are part of a power structure (or struggle), part of the way in-groups of various sorts delineate their discursive boundaries, name and expel the Other, express and reinforce their bonds, their sense of being "at home" with each other.

Given the nature of the dominant ideology and social ethos of society, the self is represented by the white man, leaving people of different races in the category of the other. Reinforcement of this division is marked via language and a dominant group may resort to metaphor in order to oppress and belittle the other, imposing their ideology through linguistic means.

One conventional way of categorizing otherness is through food-based metaphors. Figurative expressions drawing on the source domain of foods abound in English. Certainly, the significance of food for human beings rests in its simultaneous dimension, at the crossroads between the biological and the socio-cultural. Not only is food vital for the survival of people, but it is also charged with strong cultural connotations which appeal to a shared history. From the very 
first encounters to present-day migratory movements, food has always been part and parcel of human interaction and communication. It is not surprising, then, that ethnic or national groups traditionally define themselves, while denigrating others, by asserting the superiority of the foods they eat.

In the first place, dehumanization takes place by identifying people with foodstuffs. Certainly, within the hierarchical organization of THE GREAT CHAIN OF BEING humans stand above foods and, therefore, by equating the former with the latter people are being reduced to products, which, in the best case scenario, are to be consumed or, by contrast, are to be done away with because of the revulsion and disgust produced by them. Appealing to the senses by means of food-based metaphors awakens the most basic primary instincts of people, which could explain the negative connotations attached to most of the figurative senses of food when applied to different ethnic or racial groups.

In addition, food metaphors prove extremely fruitful to draw boundaries between the us versus the others because the very process of food intake represents a boundary between the outside and the inside of a person's body. Assimilation or rejection of a foodstuff, then, might run parallel to acceptance or ostracism of a particular group. This notion of boundary drawing, which is at the core of racism itself, is indirectly conveyed through the culinary terms analyzed in these pages. By showing repugnance and rejection towards the diets of others, discrimination is reinforced.

As a matter of fact, the present analysis has shed some light on how figurative terms drawing from the domain of food not only highlight different gastronomic traditions (e. g. dog-eaters), but also stress more subtle differences in terms of physical attributes, such as skin (e. g. cherry) or hair color (e. g. carrot heads), size (e. g. rice balls) and height (e. g. pip) or facial features (e. g. pancake face), job qualifications (e. g. berry-pickers), social status (e. g. Ritz cracker), are reminiscent of cruel practices (e. g. apple), highlight the existence of immigrants (e. g. pomegranate) along with ways of immigration (e. g. jumping bean) and even sanction acculturation (e. g. bananas) and interracial relations (e. g. white chocolate).

The negative views condensed in the figurative uses of the foodstuffs dealt with are truly discriminatory and as such constitute a form of racism. Apparently far removed from overtly racist practices of slavery, lynching, segregation or apartheid of bygone days, they serve the same purpose when it comes to marginalizing and excluding minorities, ethnic or racial groups.

From a strictly linguistic point of view, at first sight these metaphors do not represent the obvious bigotry of overtly racist slurs such as nigger, slant-eyed or spic, which are regarded as taboo today and tend to be avoided for reasons of sensitivity and political correctness. Yet, they conform to a more subtle, new form of racism which is manifested in discourse (see van Dijk 1987, 2000).

This "new racism" is veiled, indirect, subtle and therefore finds a powerful transmitter of prejudice in metaphor. ${ }^{29}$ The choice of metaphor as a vehicle to transmit negative stereotyped images of other races or nations proves highly effective due to the way metaphor works since it

\footnotetext{
${ }^{29} \mathrm{~A}$ key distinction is made between "old/traditional racism" and "new racism." The former refers to past practices of discrimination, segregation, lynching, and slavery whereas the latter focuses on contemporary forms of ethnic or racial inequality manifested in the social, linguistic and cognitive level (see van Dijk 2000: 34).
} 
allows the language user to talk about one domain of experience in terms of a completely different one (see Low 1998, Kittay 1987). Because metaphor operates with two domains simultaneously, the overlapping of such domains in the transfer from a source to a target will inevitably hide certain aspects of the source domain (see Lakoff/Johnson 1980). In this regard, Low (1988:27) states that in the metaphorical mapping of one domain onto another there is "a price" to be paid: "the price is that the fact that a vehicle highlights one aspect of the topic also implies that it plays down, or hides, others" (ibd.: 27) and he continues to say that this hiding mechanism inherent in the very functioning of metaphor is essential "when what is hidden is unpleasant [...] or personally disadvantageous to the speaker" (ibd.). Hence, because the entailments may very well be only partially understood, they may be covert means of maintaining values which are damaging to a particular group (MacArthur 2005).

As a corollary, an analysis about the relationship motivating metaphorical identifications of people with foods should be carried out with caution because, more often than not, such correspondences may hide important considerations about the way people understand other groups and their role in society. On the surface level food-related metaphors simply seem to highlight different food choices of people, whether for religious, geographical, cultural, or socio-economic reasons. However, on a deeper level, the very same beliefs used in traditional racism, namely, physiological differences such as complexion, height, size or physical features, which served to justify segregation and oppression, are equally transmitted.

Demeaning characterizations of human groups are therefore conveyed through the figurative usages of the foodstuffs seen in these pages. The problem is that, within this new form of racism, the aforementioned figurative usages have become so commonplace in language that their original intent may no longer be discerned, particularly obvious in the case of those metaphors based on rhyming patterns. Hence, these metaphors that rely on foodstuffs are posited as truth and accepted at face value.

As a matter of fact, the success of these metaphors is well attested not only in their widespread usage and acceptance, but also in the metaphorical networks generated by them. Such spin-offs, apart from belittling groups due to their skin color (e. g. black/pinto/white bean), physical attributes (e. g. bean bag, chocolate drops) or social class (e. g. saltine/Graham/Ritz cracker), reinforce boundaries by labelling those belonging to the in-group who sympathize and mingle with the out-group (e. g. bean/chocolate dipper).

The food metaphors analyzed provide a good insight into the construction of identities as well as paving the way for racist discourse. In fact, as Vygotsky (1978) stated, our sense of identity is forged from our interaction with others and it is in this exchange of metaphors or social etiquettes that individuals receive their social categories from which they will fashion their identities. Indeed, the entrenchment of these linguistic metaphors could be attributed to the status or power that the dominant social group represented by the white man has held in the course of history. As sociolinguists like Labov (1963) and Milroy (1987) have found, the introduction, maintenance and perpetuation of linguistic forms seems to respond to the power exercised by the privileged position a particular social group has within the community. In this sense, because, borrowing MacArthur's (2005: 81) metaphor, "THE SELF IS RELEVANT OTHERS", the members of a group will conform to the behavior and mores of their peers, adapting themselves linguistically to the speech of their relevant others. Therefore, through 
these food metaphors, people are linguistically socialized and led to believe that some groups are inferior to others because of differences in matters such as food.

\section{Conclusion}

An everyday act like eating can be transformed into food for racism. Food-based metaphors are cooked with the ingredients of traditional racism, digested and metabolized in bloodstream society. The aisles of supermarkets will be full of exotic products, international restaurants will continue branching off but food is still a fruitful ingredient in the propagation of racism. People should be made aware of the racist ideology conveyed in these food metaphors and eat up those words.

\section{References}

Adams, Carol (1990): The Sexual Politics of Meat. A Feminist-Vegetarian Critical Theory. New York: Continuum.

Altman, Meryl (1990): "How Not To Do Things with Metaphors We Live by". College English 52/5: 495-506.

Barcelona, Antonio (ed.) (2003): Metaphor and Metonymy at the Crossroads. Berlin/New York: Mouton de Gruyter.

Bell, David/Gill, Valentine (1997): "Consuming Geographies. We Are Where We Eat". London/New York: Routledge.

Bendix, Regina (1993): "Of Mohrenköpfe and Japanesen. Swiss Images of the Foreign". Journal of Folklore Research 30/1: 15-28.

Berrada, Khalid/M'sik, Ben (2007): "Food Metaphors. A Contrastive Approach." metaphorik.de 13/2007: 7-38. http://www.metaphorik.de/sites/www.metaphorik.de/files/ journal-pdf/13_2007_berrada.pdf, accessed October 24, 2014.

Bloemraad, Irene (2011): "'Two Peas in a Pod', 'Apples and Oranges', and Other Food Metaphors Comparing Canada and the United States". American Behavioral Scientist 55/9: 11311159.

British National Corpus. http://www.natcorp.ox.ac.uk/, accessed October 28, 2014.

Bruegel, Martin/Laurioux, Bruno (2002): Histoire et identités alimentaires en Europe. Paris: Hachette.

Callies, Marcus/Zimmermann, Rüdiger (eds.) (2002): Cross-Cultural Metaphors. Investigating Domain Mappings Across Cultures. Marburg: Druckzentrum der Philipps-Universität.

Calvo, Clara (1998): "Ideology and Women's Clothes. Fashion Jargon in the Daily Press". In: Hernández, José I. A./Guijarro, Arsenio/Downing Rothwell, Ángela (eds.): Patterns in Discourse and Text. Ensayos de análisis del discurso en lengua inglesa. Cuenca, Ediciones de la Universidad de Castilla-La Mancha: 63-79.

Charteris-Black, John (2006): "Britain as a Container. Immigration Metaphors in the 2005 Election Campaign". Discourse \& Society 17/5: 563-581.

Chiarung, Lu (2012): "Eating Is Not an Easy Task. Understanding Cultural Values via Proverbs". Japanese Studies Journal 29/1: 63-79.

Committee on Immigration (ed.) (1911): Dictionary of Races or Peoples. Washington: Government Printing Office. (= Reports of the U. S. Immigration Commission 1907-1910). https://archive.org/details/dictionaryraces00folkgoog, accessed October 28, 2014. 
Complex Magazine (ed.) (2013): "Racist Food Advertisements". Complex October 26, 2013. http://www.complex.com/city-guide/2013/10/racist-food-advertisements/, accessed October 28, 2014.

Corpus Concordance English. http://lextutor.ca/conc/eng/, accessed October 28, 2014.

Counihan, Carole/Van Esterik, Penny (1997): Food and Culture. A Reader. New York: Routledge.

Coviello, Jerah/Borgerson, Janet (2004): "Tracing Parallel Oppressions. A Feminist Ontology of Women and Animals". http://www.academia.edu/9426462/Tracing_Parallel_ Oppressions_A_Feminist_Ontology_of_Women_and_Animals, accessed December 16, 2014.

David-C (2011): "Racism in Advertising". owni.eu March 12, 2011. http://owni.eu/2011/03/12/ racism-in-advertising-50-shocking-examples/, accessed October 28, 2014.

Davies, Mark (ed.) (2012): Corpus of Contemporary American English. http://corpus.byu.edu/ coca/, accessed October 28, 2014.

Deignan, Alice (2003): "Metaphorical Expressions and Culture. An Indirect Link". Metaphor and Symbol 18/1: 255-271.

Deignan, Alice (2005): Metaphor and Corpus Linguistics. Amsterdam: John Benjamins.

Dijk, Teun A. van (1987): Communicating Racism. Ethnic Prejudice in Thought and Talk. London: Sage Publications.

Dijk, Teun A. van (2000): "New(s) Racism. A Discourse Analytical Approach". In: Cottle, Simon (ed.): Ethnic Minorities and the Media. London, Open University Press: 33-49.

Dirven, René/Pörings, Ralph (2002): Metaphor and Metonymy in Comparison and Contrast. Berlin/New York: Mouton de Gruyter.

Drew, Paul/Holt, Elizabeth (1998): "Figures of Speech. Figurative Expressions and the Management of Topic Transition in Conversation". Language in Society 27/4: 495-522.

Duckworth, Ted (2014): A Dictionary of English Slang. http://www.peevish.co.uk/slang/, accessed October 28, 2014.

"Ethnic Slur". WordNet 3.0. Princeton University: Clipart.com/Farlex Inc. http://www.thefreedictionary.com/ethnic+slur, accessed October 28, 2014.

Evans, Bergen/Evans, Cornelia (eds.) (1957): A Dictionary of Contemporary American Usage. New York: Random House.

Farquhar, Judith (2002): Appetites. Food and Sex in Postsocialist China. Durham: Duke University Press.

Faycel, Dahklaoui (2012): "Food Metaphors in Tunisian Arabic Proverbs". Rice Working Papers in Linguistics 3/1: 1-23. http://scholarship.rice.edu/bitstream/handle/1911/64168 /RWPL3_Faycel.pdf?sequence=1, accessed October 27, 2014.

Fernando, Chitra (1996): Idioms and Idiomaticity. Oxford: Oxford University Press.

Fischler, Claude (1988): "Food, Self and Identity". Social Science Information 27/1: 275-293.

Fredrickson, George M. (2009): Racism. A Short History. Princeton: Princeton University Press.

Galván Tudela, José Alberto (1998): "El ajíaco, una metáfora culinaria sobre la cubanía (a propósito de la inmigración canaria a Cuba: 1880-1930)". In: Morales Padrón, Francismo (ed.): Papers from the XIII Coloquio de Historia Canario-Americana. Las Palmas, Ediciones del Cabildo de Gran Canaria: 2621-2639. 
Gerhardt, Cornelia (ed.) (2013): Culinary Linguistics. The Chef's Special. Philadelphia: Benjamins.

Gibbs, Raymond W. (1994): The Poetics of Mind. Figurative Thought, Language and Understanding. New York: Cambridge University Press.

Gibbs, Raymond W. (2006): Embodiment and Cognition. Cambridge: Cambridge University Press.

Gibbs, Raymond/Steen Gerard J. (eds.) (1999): Metaphor in Cognitive Linguistics. Amsterdam: John Benjamins.

Gloor, LeAna (2005): "From the Melting Pot to the Tossed Salad Metaphor. Why Coercive Assimilation Lacks the Flavors Americans Crave". Hohonu 4: 29-32. http://hilo.hawaii.edu/ academics/hohonu/documents/Vol04x06FromtheMeltingPot.pdf, accessed October 27, 2014.

Goschler, Juliana (2005): "Embodiment and Body Metaphors." metaphorik.de 9/2005: 33-52. http://www.metaphorik.de/sites/www.metaphorik.de/files/journal-pdf/09_2005_ goschler.pdf, accessed October 27, 2014.

Grady, Joseph. (1997): "THEORIES ARE BUILDINGS revisited". Cognitive Linguistics 8/1: 267-290.

Halupka-Rešetar, Sabina (2003): "Animal Names Used in Addressing People in Serbian". Journal of Pragmatics 35/1: 1891-1902.

Harper, Douglas (2014): Online Etymology Dictionary. http://www.etymonline.com/, accessed October 28, 2014.

Harris, Marvin (1985): Good to Eat. Riddles of Food and Culture. New York: Touchstone/Simon \& Schuster.

Harvey, Arnold D. (2007): Body Politic. Political Metaphor and Political Violence. Cambridge: Cambridge Scholars Publishing.

Heine, Bernd et al. (1991a): Grammaticalization. A Conceptual Framework. Chicago: University of Chicago Press.

Heine, Bernd et al. (1991b): "From Cognition to Grammar. Evidence from African Languages". In: Closs Traugott, Elizabeth/Heine, Bernd (eds.): Approaches to Grammaticalization. Vol. 1. Amsterdam, Benjamins: 149-187.

Heine, Bernd/Thang, Tat (2009): "Language \& Embodiment". VNU Journal of Science, Foreign Languages 25/1: 250-256.

Hernández López, Ernesto (2008): "Law, Food, and Culture. Mexican Corn's National Identity Cooked in 'Tortilla Discourses' Post-TLC/NAFTA". St. Thomas Law Review 20/1: 573-593.

Hinnerová, Katarína (2007): Food as a Transcultural Metaphor. Food Imagery in Contemporary Multicultural Women Writing in Canada. Masaryk University of Brno. Doctoral Dissertation. http://is.muni.cz/th/74496/ff_m/?lang=en, accessed October 24, 2014.

Hiroko, Takeda (2008): "Delicious Food in a Beautiful Country. Nationhood and Nationalism in Discourses on Food in Contemporary Japan". Studies in Ethnicity and Nationalism 8/1: $5-30$.

Holahan, Dana Elizabeth (2002): "Ramadas y empanadas. La comida como metáfora identitaria". CyberHumanitatis 23. http://web.uchile.cl/vignette/cyberhumanitatis/CDA/ texto_simple2/0,1255,SCID\%253D3534\%2526ISID\%253D258,00.html, accessed October 27, 2014. 
Hughes, Geoffrey (1991): Swearing. A Social History of Foul Language, Oaths and Profanity in English. Oxford/Cambridge: Blackwell.

Internet Racial Slang Database. http://www.pdftop.com/ebook/internet+racial+slur+database/, accessed December 15, 2014.

Jaggar, Philip/Buba, Malami (2009): "Metaphorical Extensions of 'Eat' and 'Drink' in Hausa". In: Newman, John (ed.): The Linguistics of Eating and Drinking. Amsterdam/Philadelphia, John Benjamins: 229-251.

Johnson, Mark (1987): The Body in the Mind. Chicago: University of Chicago Press.

Khudhair, Bushra (2011): "Metaphors in Iraqi Arabic Variety. A Cognitive-semantic Study". International Proceedings of Economics Development \& Research 26/1: 228-233.

Kittay, Eva (1987): Metaphor. Its Cognitive Force and Linguistic Structure. Oxford: Clarendon Press.

Korthals, Michiel (2008): "Food as a Source and Target of Metaphors. Inclusion and Exclusion of Foodstuffs and Persons through Metaphors". Configurations 16/1:77-92.

Kövecses, Zoltán (2006): Language, Mind, and Culture. A Practical Introduction. New York: Oxford University Press.

Kövecses, Zoltán (2005): Metaphor in Culture. Universality and Variation. New York: Cambridge University Press.

Labov, William (1963): "The Social Motivation of Sound Change". Word 19/1: 273-309.

Lakoff, George/Johnson, Mark (1980): Metaphors We Live By. Chicago/London: Chicago University Press.

Lakoff, George/Turner, Mark (1989): More than Cool Reason. A Field Guide to Poetic Metaphor. Chicago: University of Chicago Press.

Leach, Edmund (1964): "Anthropological Aspects of Language. Animal Categories and Verbal Abuse". In: Lenneberg, Eric H. (ed.): New Directions in the Study of Language. Massachusetts, MIT Press: 23-63.

Leeds-Hurwitz, Wendy (1993): "Food as Sign and Code". In: Leeds-Hurwitz, Wendy (ed.): Semiotics and Communication. Signs, Codes, Cultures. New York, Lawrence Erlbaum Associates: $83-103$.

Lehrer, Adrienne (1990): "As American as Apple Pie - and Sushi and Bagels. The Semiotics of Food and Drink". In: Sebeok, Thomas/Umiker-Sebeok, Jean (eds.): Recent Developments in Theory and History. The Semiotic Web 1990. Berlin, Mouton de Gruyter. 389-401.

Leizaloa, Aitzpea (2006): "Matching National Stereotypes? Eating and Drinking in the Basque Borderland". Anthropological Notebooks 12/1: 79-94.

Lighter, Jonathan (1994): Historical Dictionary of American Slang. New York: Random House. Lillo, Antonio (2001): "From Alsatian Dog to Wooden Shoe. Linguistic Xenophobia in Rhyming Slang". English Studies 82/4: 336-348.

"List of Ethnic Slurs". Wikipedia. http://en.wikipedia.org/wiki/List_of_ethnic_slurs, accessed October 28, 2014.

López-Rodríguez, Irene (2009): "Of Women, Bitches, Chickens and Vixens. Animal Metaphors for Women in English and Spanish". Culture, Language and Representation 7/1: 77-100.

Lovejoy, Arthur (1936): The Great Chain of Being. A Study of the History of an Idea. Cambridge: Harvard University Press.

Low, Graham (1988): "On Teaching Metaphor". Applied Linguistics 9/2: 125-147. 
Maalej, Zouheir (2004): "Figurative Language in Anger Expressions in Tunisian Arabic. An Extended View of Embodiment". Metaphor and Symbol 19/1: 51-75.

Maalej, Zouheir (2007): "What Food Metaphors Tell Us about Women in Tunisian Arabic. A Critical Metaphor Analysis of Embodiment". Paper presented at ICLC 10, Krakow, Poland, (15-20 July). http://faculty.ksu.edu.sa/zmaalej/Documents/2\%20Culinary\%20metaphors\% 20for\%20women\%20in\%20TA.pdf, accessed October 27, 2014.

MacArthur, Fiona (2005): "The Competent Horseman in a Horseless World. Observations on a Conventional Metaphor in Spanish and English". Metaphor and Symbol 20/1: 71-94.

Merriam-Webster (ed.) (2011): Merriam-Webster.com. http://www.merriam-webster.com, accessed October 28, 2014.

Milroy, Lesley (1987): Language and Social Networks. $2^{\text {nd }}$ ed. Oxford: Basil Blackwell.

Mintz, Sidney (1985): Sweetness and Power. The Place of Sugar in Modern History. New York: Viking.

Moon, Rosalind (1998): Fixed Expressions and Idioms in English. A Corpus-Based Approach. Oxford: Clarendon Press.

Mussolf, Andreas (2012): "The Study of Metaphor as Part of Critical Discourse Analysis". Critical Discourse Studies 9/3: 301-310.

Newman, John (1997): "Eating and Drinking as Sources of Metaphor in English". Cuadernos de Filología Inglesa 6/2: 213-231.

Nunberg, Geoffrey/Sag, Ivan A./Wasow, Thomas (1994): "Idioms". Language 20/3: 491-537.

O'Brien, Gerald (2003): "Indigestible Food, Conquering Hordes, and Waste Materials. Metaphors of Immigrants and the Early Immigration Restriction Debate in the United States". Metaphor \& Symbol 18/1: 33-47.

Partridge, Eric (ed.) (1984): A Dictionary of Slang and Unconventional English. London: Routledge.

Partridge, Eric (ed.) (1949): A Dictionary of the Underworld. London: Routledge/Kegan Paul. Phuong Tam, Do Th. (2009): "Food Metaphors in English and Vietnamese. A Contrastive Analysis". Online paper. http://khoaanh.net/_upload/CA2009/4C06_DoThiPhuongTam_ FoodMetaphorinEnglishandVietnamese.doc, accessed October 27, 2014.

Rader, Walter (ed.) (2014): The Online Slang Dictionary. http://onlineslangdictionary.com/, accessed October 28, 2014.

Rash, Felicity (2005): "A Database of Metaphors in Adolf Hitler's "Mein Kampf"". metaphorik.de 9/2005: 74-111. http:/www.metaphorik.de/sites/www.metaphorik.de/files/ journal-pdf/09_2005_rash.pdf, accessed October 27, 2014.

Raviv, Yael (2001): "National Identity on a Plate". Palestine-Israel Journal 8/4. http://www.pij.org/details.php?id=805, accessed October 27, 2014.

Roget, Peter M. (2002): Roget's Thesaurus of English Words and Phrases. $3^{\text {rd }}$ ed. London: Penguin.

Rubba, Jo (1994): "Grammaticalization and Semantic Change. A Case Study of Preposition Development". In: Pagliuca, William (ed.): Perspectives on Grammaticalization. Amsterdam, Benjamins: 81-101.

Santa Ana, Otto (1999): "Like an Animal I was Treated. Anti-Immigrant Metaphor in US Public Discourse". Discourse \& Society 10/2: 191-224. 
Scholliers, Peter (ed.) (2001): Food, Drink and Identity. Cooking, Eating and Drinking in Europe since the Middle Ages. New York: Bloomsbury Academy.

Schulz, Muriel (1975): "The Semantic Derogation of Women". In: Thorne, Barrie/Henley, Nancy (eds.): Language and Sex. Difference and Dominance. Rowley/MA, Newbury House: 64-75.

Simpson, John/Weiner, Edmund S. C. (1989): The Oxford English Dictionary. $2^{\text {nd }}$ ed. Oxford: Clarendon Press.

Sinclair, John (ed.) (2002): Collins Cobuild Dictionary of Idioms. Glasgow: Harper Collins.

"Slang". Urban Dictionary. http://www.urbandictionary.com/define.php?term=slang, accessed October 28, 2014.

Smith, Anthony (1994): "Gastronomy or Geology? The Role of Nationalism in the Reconstruction of Nations". Nations and Nationalism 1/1:3-23.

Spiering, Menno (2006): "Food, Phagophobia and English National Identity". European Studies 22/1: 31-48.

Stevenson, Robert L. (1913): "Foreign Children". http://www.bartleby.com/188/129.html, accessed October 28, 2014.

Taylor, John (2003): "Polysemy's Paradoxes". Language Sciences 25/1: 637-655.

The Racial Slur Database. 1999. http://www.rsdb.org/, accessed October 28, 2014.

Tilyard, Eustace (1959): The Elizabethan World Picture. New York: Vintage Books.

Vaclavíková, Eva (2010): Idioms of Colour. A Corpus-based Study. Masaryk University. Department of English and American Studies Press. MA Thesis.

Vygotsky, Lev S. (1978): Mind in Society. The Development of Higher Psychological Processes. Cambridge: Harvard University Press.

Wilkinson, Peter (ed.) (2002): Thesaurus of Traditional English Metaphors. London/New York: Routledge.

Wilson, Clint C./Gutierrez, Felix/Chao, Lena (eds.) (2012): Racism, Sexism, and the Media. Multicultural Issues into the New Communications Age. London: Sage Publications. 